\title{
Mercado audiovisual, políticas públicas e educação: os impactos de uma escola de audiovisual para a economia criativa na região do $\mathrm{ABC}$ Paulista
}

\author{
Audiovisual market, public policies, and education: \\ the impacts of an audiovisual school on the creative economy in the \\ São Paulo ABC region
}

Mercado audiovisual, políticas públicas y educación: los impactos de una escuela de audiovisual en la economía creativa en la región del ABC de São Paulo

\author{
Denise Szabo \\ Universidade Anhembi Morumbi - PPGCOM-UAM - Brasil \\ ORCID: https://orcid.org/0000-0001-9066-0317 \\ Endereço currículo Plataforma Lattes: http://lattes.cnpq.br/6205326849451878 \\ E-mail: deniseszabo@gmail.com \\ Nara Lya Cabral Scabin \\ Universidade Anhembi Morumbi - PPGCOM-UAM - Brasil \\ ORCID: https://orcid.org/0000-0002-7121-1142 \\ Endereço currículo Plataforma Lattes: http://lattes.cnpq.br/8600661274396116 \\ E-mail: naralyacabral@yahoo.com.br
}

\begin{abstract}
Resumo: Partindo de pesquisa bibliográfica sobre as políticas públicas de incentivo ao cinema brasileiro recente e o contexto de transformações socioculturais decorrentes da digitalização do audiovisual, este artigo busca refletir sobre o papel do Estado no fomento do audiovisual, especialmente no que diz respeito à formação de mão de obra qualificada para atuação em um mercado em crescimento. Para tanto, destaca o caso do Centro de Audiovisual de São Bernardo do Campo (CAV), uma escola pública de audiovisual atuante, desde 2012, na região do ABC paulista. Com base no exame de alguns indicadores específicos, o trabalho evidencia que os impactos do CAV passam pelo incremento da economia criativa na região, ao mesmo tempo em que desenvolve competências para a atuação em uma cultura de participação e convergência midiáticas.
\end{abstract}

Palavras-chave: Mercado audiovisual. Políticas públicas. Digitalização. Centro de Audiovisual de São Bernardo do Campo. Economia criativa. 


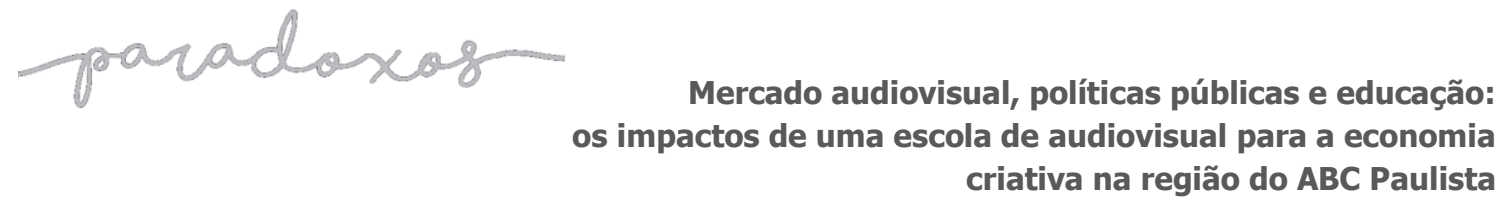

SZABO, SCABIN, 2021

\begin{abstract}
Based on bibliographic research on public policies to encourage recent Brazilian cinema and the context of sociocultural transformations caused by the digitalization of the audiovisual, this article seeks to reflect on the role of the State in promoting the audiovisual, especially about the training of qualified professionals to operate in a growing market. Therefore, it highlights the case of the Centro de Audiovisual de São Bernardo do Campo (CAV), a public audiovisual school operating since 2012 in the region known as "ABC", in the state of São Paulo, Brazil. Based on the examination of specific indicators, the work shows that the CAV impacts involve the increment of the creative economy in the region, at the same time as it develops competences for acting in a culture of media participation and convergence.
\end{abstract}

Keywords: Audiovisual market. Public policies. Digitalization. Centro de Audiovisual de São Bernardo do Campo. Creative economy.

Resumen: A partir de una investigación bibliográfica sobre políticas públicas de incentivo al cine brasileño reciente y el contexto de transformaciones socioculturales derivadas de la digitalización del audiovisual, este artículo busca reflexionar sobre el papel del Estado en la promoción del audiovisual, especialmente en relación con la formación de profesionales calificados para operar en un mercado en crecimiento. Para ello, destaca el caso del Centro de Audiovisual de São Bernardo do Campo (CAV), una escuela pública audiovisual que opera desde 2012 en la región conocida como "ABC", en el estado brasileño de São Paulo. A partir del examen de indicadores específicos, el trabajo muestra que el CAV incrementa la economía creativa en la región, al mismo tiempo que favorece el desarrollo de competencias para actuar en una cultura de participación y convergencia mediáticas.

Palabras-clave: Mercado audiovisual. Políticas públicas. Digitalización. Centro de Audiovisual de São Bernardo do Campo. Economía creativa.

\title{
Introdução
}

Há três décadas, o governo Collor marcava um dos períodos mais duros para a história do mercado cinematográfico brasileiro. Com o fim da Embrafilme, estatal responsável pelo fomento e distribuição de filmes nacionais nas décadas de 1970 e 1980 , à luz de uma política econômica neoliberal, é possível dizer que a extinção do fomento ao cinema nacional significou também o fim do fomento à inovação no audiovisual. 
Com o impeachment de Collor, a posse do vice-presidente Itamar Franco e os esforços do recém empossado Secretário de Cultura Sérgio Paulo Rouanet, a retomada das políticas culturais deu-se de forma paulatina. Foram marcos fundamentais do período a Lei no 8.313/91, conhecida como "Lei Rouanet", e a Lei no 8.685/93, ou "Lei do Audiovisual" (TRINDADE, 2014).

Tais mecanismos de incentivo trouxeram vida nova ao audiovisual brasileiro, inaugurando a fase que ficaria conhecida como "Cinema de Retomada". O movimento de retomada do cinema brasileiro encontraria ainda importante fator de propulsão na criação, em 2001, da Agência Nacional do Cinema, a ANCINE, uma autarquia especial que regula, fiscaliza e fomenta o mercado audiovisual no Brasil.

Ao mesmo tempo, o campo audiovisual ${ }^{1}$ dos anos 2000 atravessava significativas transformações tecnológicas Com surgimento e popularização vídeo digital em alta definição, uma profunda mudança de paradigma altera os hábitos de produção e consumo audiovisuais. Isso porque o processo de digitalização das informações permitiu a produção de cópias sem perda da qualidade em relação ao original, além da ampliação das janelas de exibição e barateamento da produção.

Assim, além de mudar o padrão de produção e exibição dos filmes de grande orçamento, a digitalização também viabilizou modelos paralelos de produção e distribuição de conteúdos, ampliando o espaço para criações amadoras e reconceituando outros aspectos da cultura, com a emergência de novos modos a participação cultural e política, a revisão de expectativas econômicas e a reconfiguração das estruturas legais que regulam os mercados culturais (JENKINS; GREEN; FORD, 2014).

Esse contexto de barateamento decorrente da digitalização tecnológica, por um lado, somado à necessidade de formação mão de obra qualificada para atuar no emergente mercado audiovisual brasileiro dos anos 2000, por outro lado, desaguaria em um esforço,

\footnotetext{
${ }^{1}$ Embora fuja às nossas possibilidades desenvolver uma discussão teórica extensa em torno do conceito de "campo" na extensão deste artigo, convém observar que a ideia de "campo audiovisual" aqui referida é animada pelas proposições do sociólogo Pierre Bourdieu que buscou, com sua teoria dos campos, desenvolver um modelo geral para pensarmos as sociedades diferenciadas. Cada campo, para o autor, é um microcosmo do espaço social, relativamente autônomo, com um habitus próprio, estruturado a partir das posições ocupadas pelos diferentes agentes do campo e marcado pelas lutas decorrentes da concorrência entre esses mesmos agentes, que disputam a obtenção do capital específico do campo, desigualmente específico (LAHIRE, 2017).
} 


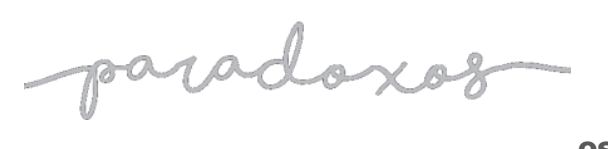

Mercado audiovisual, políticas públicas e educação: os impactos de uma escola de audiovisual para a economia criativa na região do $\mathrm{ABC}$ Paulista

SZABO, SCABIN, 2021

por parte de instituições públicas (e privadas), de criação de cursos de linguagem audiovisual Brasil adentro, voltados tanto para a linguagem de live action quanto para animação.

É precisamente sobre essa conjunção de fatores - culturais, sociais, históricos, políticos, econômicos - que se debruça o presente artigo ao apresentar os resultados parciais de uma pesquisa de mestrado em curso no Programa de Pós-graduação em Comunicação da Universidade Anhembi Morumbi, em São Paulo. Em um primeiro momento, com base em pesquisa bibliográfica, realizamos uma breve recuperação tanto das políticas públicas de incentivo ao mercado audiovisual brasileiro recente quanto do contexto de transformações socioculturais decorrentes da digitalização e expansão do mercado audiovisual no Brasil.

Em seguida, localizamos, em meio a tais processos, o aumento da oferta de iniciativas voltadas ao ensino e formação de profissionais para atuação no campo audiovisual. A fim de compreender melhor esse cenário, destacamos o caso de uma escola pública de audiovisual localizada na região do chamado "ABC" paulista 2 : o Centro de Audiovisual de São Bernardo do Campo (CAV), inaugurado em 2012 como primeira etapa do projeto Nova Vera Cruz, uma das inúmeras tentativas de revitalização da antiga Cia Cinematográfica Vera Cruz.

Dessa forma, este trabalho busca refletir sobre os impactos do Centro de Audiovisual de São Bernardo do Campo para a economia criativa na região do ABC paulista. Considerada a partir da conceituação proposta por Howkins (2012), a economia criativa compreende atividades que encontram no capital intelectual matéria-prima fundamental para a produção e distribuição de bens e serviços. Dessa forma, abarca negócios ligados às indústrias criativas e estimula a geração de renda, criação de empregos e produção de receitas, ao mesmo tempo em que favorece o desenvolvimento e a diversidade cultural (SEBRAE, s.d.).

Para tanto, examinamos a atuação do CAV a partir de dois indicadores específicos: estímulo à abertura de novos negócios, até junho de 2021, e participação de pessoas envolvidas no projeto em editais municipais da Lei Aldir Blanc, em 2020. As reflexões desenvolvidas sugerem um incremento da economia criativa do município de São Bernardo do Campo e cidades vizinhas, chamando a atenção para o papel fundamental desempenhado

\footnotetext{
${ }^{2}$ Nomeado em referência às iniciais dos nomes de três cidades industriais (Santo André, São Bernardo do Campo e São Caetano do Sul) localizadas entre a capital paulista e o litoral, o ABC compreende a região composta, oficialmente, por sete cidades da região metropolitana de São Paulo: Santo André, São Bernardo do Campo, São Caetano do Sul, Diadema, Mauá, Ribeirão Pires e Rio Grande da Serra.
} 


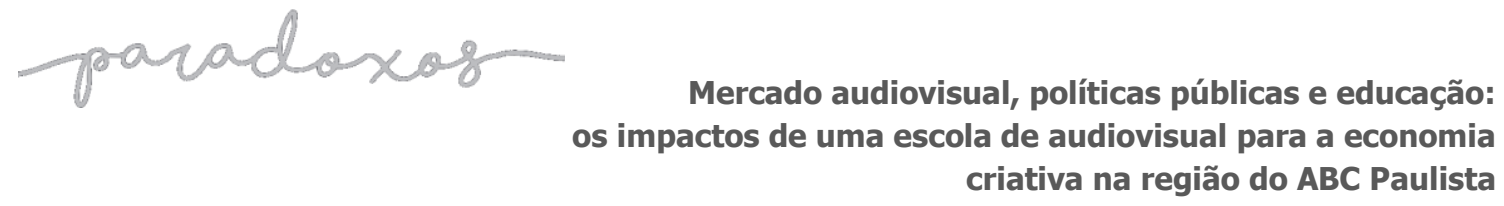

SZABO, SCABIN, 2021

pelo Estado, por meio de políticas públicas para a cultura, no fomento das indústrias criativas e, mais especificamente, no fortalecimento do mercado audiovisual brasileiro.

\section{O mercado audiovisual brasileiro recente e as políticas de incentivo}

A historiografia nos conta que o cinema brasileiro atravessou uma série de ciclos ou, como preferiu definir o cineasta e crítico Alex Viany (apud ANCINE, 2017), "surtos"-, e o Estado brasileiro está presente na empreitada cinematográfica desde a década de 1930, com a criação do Instituto Nacional de Cinema Educativo (INCE).

No entanto, durante o governo Collor, o mercado cinematográfico brasileiro vivia uma das piores fases de sua história. Com a extinção da Embrafilme, empresa estatal criada durante a ditadura militar, que fomentava e distribuía a produção de filmes nacionais em meados dos anos 1970 e 1980, o mercado nacional se viu resumido a algumas produções independentes para a TV, quase todas elas direcionadas ao mercado publicitário (SEBRAE, 2015). Tal afirmação pode ser verificada nas considerações de que:

O Governo Collor seguia os preceitos do pensamento político neoliberal, que se tornava hegemônico no país, e somava-se a isso uma genuína "fobia do estado", desencadeada pelo fim de um regime autoritário. [...] Em suma, o governo reposicionou a cultura como apenas mais uma mercadoria que deveria caminhar com suas próprias pernas na livre concorrência onde o Estado deveria ter um papel mínimo: a chamada economia de mercado (TRINDADE, 2014, p.31).

Embora as medidas do governo Collor tivessem apoio popular, inclusive de boa parte da chamada "classe cinematográfica", a crise econômica que culminou no impeachment do então presidente, e a queda significativa na quantidade de obras brasileiras, colocaram em xeque as medidas tomadas pela equipe econômica, afinal, as produções nacionais independentes praticamente "morreram", a ponto de, em 1992, apenas três filmes brasileiros chegarem às salas de cinema (GATTI, 2008).

Com a política econômica de Collor, a extinção do fomento ao cinema nacional significou também o fim do fomento à inovação no mercado audiovisual, pois a inexistência de políticas públicas para a cultura no Brasil do final do século XX, e o 


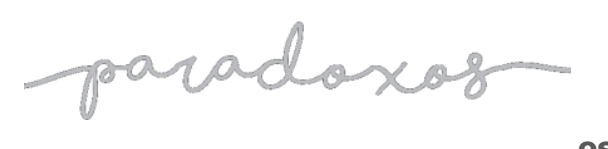

Mercado audiovisual, políticas públicas e educação: os impactos de uma escola de audiovisual para a economia criativa na região do $\mathrm{ABC}$ Paulista

SZABO, SCABIN, 2021

evidente despencar na quantidade de produções, gerou um reboliço no setor artísticocultural. Com a posse do vice-presidente Itamar Franco e os esforços do recémempossado Secretário de Cultura Sérgio Paulo Rouanet, progressivamente houve a retomada das políticas culturais que teve como produtos imediatos a Lei $\mathrm{n}^{\circ}$ 8.313/91 (Lei Rouanet) e a Lei $n^{\circ}$ 8.685/93 (Lei do Audiovisual), entre outros mecanismos de incentivo à cultura (TRINDADE, 2014).

Ainda que venham sendo objetos de crítica de diferentes matizes ideológicos, tais mecanismos de incentivo trouxeram vida nova ao cinema nacional, levando ao período conhecido historicamente como Retomada do Cinema Brasileiro, o qual se caracteriza por uma variedade de filmes, diferentes entre si, sem gêneros específicos, realizados via lei de incentivo e com financiamentos complementares (GATTI, 2005). O movimento de retomada do cinema nacional, numa via de mão dupla, culminou, em 2001, na criação da ANCINE, que, na forma de autarquia especial, regula, fiscaliza e fomenta o mercado audiovisual brasileiro ${ }^{3}$.

A criação da ANCINE e o fortalecimento do fomento à produção audiovisual modificou o cenário de conteúdos nacionais, o que repercutiu em aumento da quantidade de público e retorno dos filmes brasileiros aos festivais de cinema e à televisão. Porém, em plenos anos 2000, olhar para a produção cinematográfica repartindo televisão e cinema como mercados muito distintos parecia equivocado, tanto que a própria agência reformulou suas políticas e passou a enxergar a criação de conteúdo para diferentes segmentos de maneira mais ampla, visando a uma política de expansão do mercado e novas oportunidades de negócio (ANCINE, 2017).

Dentre as medidas encabeçadas pela agência, houve, além do fomento à produção, a expansão do parque exibidor e a criação, em 2006, do Fundo Setorial do Audiovisual (FSA), que buscou viabilizar uma forma diferente de financiar o setor para além das Leis de Incentivo. O fundo prevê retorno de investimento para as obras que dão lucro, a fim de retroalimentar o próprio mecanismo de incentivo. Ao mesmo tempo,

\footnotetext{
${ }^{3}$ A Agência Nacional do Cinema - ANCINE foi criada em 6 de setembro de 2001, pelo art. 5 (da Medida Provisória $\mathrm{n}^{\circ}$ 2.228-1), na forma de autarquia especial, com autonomia administrativa e financeira, e vinculada, de acordo com o texto da MP, ao Ministério do Desenvolvimento, Indústria e Comércio Exterior. Somente em outubro de 2003, a ANCINE teve sua vinculação fixada ao Ministério da Cultura.
} 
Mercado audiovisual, políticas públicas e educação: os impactos de uma escola de audiovisual para a economia

criativa na região do ABC Paulista

SZABO, SCABIN, 2021

iniciativas como a articulação política para a criação da Lei 12.485 , conhecida como "Lei do Cabo", de 12 de setembro de 2011, que removeu barreiras à expansão da TV paga e redefiniu o ambiente regulatório do audiovisual ao obrigar o carregamento de conteúdo brasileiro pelos canais e empacotadoras (ANCINE, 2017), também fortaleceram o cenário produtivo e exibidor brasileiro ${ }^{4}$.

Dentre as muitas linhas de investimento do Fundo Setorial do Audiovisual (FSA), há uma que prevê a etapa de desenvolvimento de obras audiovisuais, ou seja, pesquisa de roteiro, formatos de linguagem, produção de episódios piloto etc. Dessa forma, em linhas gerais é possível afirmar que o Estado fomenta a etapa de maior risco, aquela em que o setor privado está pouco disposto a investir, e que possui importância fundamental à inovação no mercado audiovisual ${ }^{5}$.

Assim, se, em 2019, o audiovisual brasileiro viveu um momento de sucesso com filmes competindo entre os principais festivais nacionais e internacionais (Sundance, Berlim, Emmy Kids) e até mesmo ao Oscar ${ }^{6}$, encontrando resultados recorde de audiência como o de Minha mãe é uma peça $3^{7}$ e mantendo-se como um dos segmentos econômicos de maior crescimento no país (GEISLER, 2020) -, é porque, na última década, estabeleceu-se uma política pública clara para a pesquisa e inovação do setor. Conforme afirma a pesquisadora Daniela Geisler (2020), no mercado audiovisual brasileiro, assim como em todos os mercados audiovisuais do mundo, devido ao forte

\footnotetext{
${ }^{4}$ Dados do estudo "Impacto econômico do setor audiovisual brasileiro" (MPA-AL; SICAV, 2016), encomendado pela Motion Picture Association América Latina (MPA-AL) e pelo Sindicato Interestadual da Indústria do Audiovisual (Sicav), apontam que, em 2013, o setor do audiovisual foi responsável por $0,57 \%$ do Produto Interno Bruto (PIB) nacional, com participação similar a outros grandes setores, como têxtil, vestuário, autopeças e produtos farmacêuticos, e chegando a movimentar em torno de $\mathrm{R} \$ 15,7$ bilhões na economia brasileira.

${ }^{5}$ A cadeia produtiva do audiovisual é dividida basicamente em seis macro-elos (planejamento, préprodução, produção, pós-produção, distribuição e exibição), sendo que, na etapa do planejamento, estão inseridos pesquisa e desenvolvimento (SEBRAE, 2015). Embora pesquisar e desenvolver sejam atividades essenciais como estratégias de diferenciação e gerem competitividade e crescimento em um número cada vez maior de negócios (FUCK; VILHA, 2012), trata-se de uma empreitada de risco. Mesmo canais de televisão como a Rede Globo, que mantém internamente um setor de pesquisa e desenvolvimento de tendências de mercado e concepção de novos conteúdos, costumam apostar majoritariamente em narrativas certeiras, como adaptações de obras literárias, programas de auditório ou licenciamento de formatos que deram certo internacionalmente (PETHS, 2013).

${ }^{6}$ No Oscar 2020, o filme Democracia em Vertigem, da cineasta Pietra Costa, esteve no páreo pelo troféu de melhor documentário. Já em 2019, a série de animação brasileira Irmão do Jorel foi contemplada com o Emmy Kids.

${ }^{7} \mathrm{O}$ longa atingiu quase 12 milhões de espectadores nos cinemas e superou a audiência de Vingadores, $o$ Ultimato, tanto nos cinemas quanto na plataforma de VoD Net Now.
} 


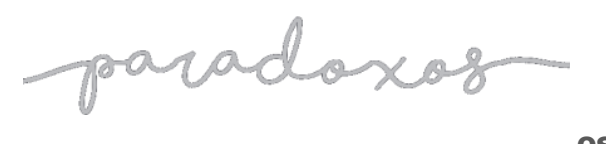

Mercado audiovisual, políticas públicas e educação: os impactos de uma escola de audiovisual para a economia criativa na região do $\mathrm{ABC}$ Paulista

SZABO, SCABIN, 2021

domínio econômico, político e cultural exercido pelos Estados Unidos, a intervenção estatal desempenha papel decisivo para promover a cinematografia nacional.

Para além das recentes políticas de incentivo descritas nesta seção, outra frente tem se revelado essencial ao fomento do audiovisual no Brasil, com algumas ações e objetos tornando-se objeto de investimento público: a formação e qualificação de mão de obra para atuação em um mercado audiovisual em expansão. Nas próximas páginas, destacamos a questão do ensino de cinema e audiovisual no país, à luz de processos de inovação tecnológica e democratização do campo audiovisual. Desse modo, a intenção é refletir, mais adiante, sobre o papel do Centro de Audiovisual de São Bernardo do Campo (CAV), uma escola pública de audiovisual, em termos de fomento da economia criativa na região do $\mathrm{ABC}$ paulista.

\section{Inovação tecnológica, expansão de mercados e o ensino de cinema e audiovisual}

O mundo da segunda metade do século XX é marcado pelo desenvolvimento e consolidação de uma série de tecnologias eletrônicas e digitais, sobretudo no campo da comunicação interativa, cuja convergência levou à criação da Internet, que talvez seja o mais revolucionário meio da era da informação (CASTELLS, 2000). No campo audiovisual, antes ainda da Internet, uma das grandes mudanças veio a partir da invenção do videoteipe, na década de 1960, que fixava imagens em movimento em fitas magnéticas por meio de impulsos eletrônicos, sendo uma alternativa à película na possibilidade de registro audiovisual. Ainda que, até o final do século XX, o vídeo tivesse qualidade muito inferior às películas, inclusive levando-se em conta alternativas menos caras ao $35 \mathrm{~mm}$ como o $16 \mathrm{~mm}$, sua possibilidade de "gravar por cima", ou seja, reaproveitar o material magnético em caso de erro, foi um convite à experimentação, além de ter fortalecido a indústria da televisão (PRIOLLIU; CLARK, 1991).

O vídeo permaneceu tecnicamente inferior às películas até o encerramento do século $\mathrm{XX}$, sendo usado principalmente no jornalismo e produções para a TV. Mas, a partir dos anos 2000, com surgimento e popularização vídeo digital em alta definição, ocorre uma profunda mudança de paradigma nos hábitos de produção e consumo audiovisuais. Afinal, o mundo passava por um processo de digitalização, que se somava à popularização, 


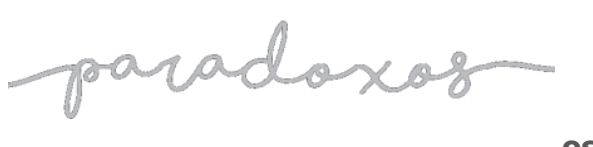

Mercado audiovisual, políticas públicas e educação: os impactos de uma escola de audiovisual para a economia criativa na região do $\mathrm{ABC}$ Paulista

SZABO, SCABIN, 2021

crescimento e posterior consolidação da Internet como plataforma tecnológica de comunicação. Importante ressaltar que todo esse processo é longo, complexo e envolve diversos fatores, mas a passagem do vídeo analógico para o vídeo digital de alta definição nada mais é do que um reflexo de um processo de evolução tecnológica das telecomunicações, bem como do aumento da capacidade de processamento de microcomputadores, que vinha gradativamente ocorrendo desde a década de 1970 e cujo boom ocorre nas duas décadas finais do século XX (CASTELLS, 2000).

Assim como em outros segmentos, o audiovisual do século XXI é marcado pela digitalização das informações, antes analógicas, o que permitiu a inumerável quantidade de cópias sem qualquer perda da qualidade entre o original, além da reprodução nos mais diversos dispositivos, como TV, computador, celular etc. (LÉVY, 1999). Essa evolução tecnológica ampliou as janelas de exibição e modificou os hábitos de produção e consumo de filmes e vídeos. Além de mudar o padrão de produção e exibição dos filmes de grande orçamento, a digitalização também viabilizou um modelo paralelo de produção e distribuição de conteúdos, abrindo espaço para que criadores ditos amadores pudessem produzir e distribuir sua produção com maior facilidade. Mais amplamente, ainda, as facilitações da mídia digital funcionam como catalisadoras para a reconceituação de outros aspectos da cultura, exigindo que sejam repensadas as relações sociais, que imaginemos de outros modos a participação cultural e política, que as expectativas econômicas sejam revistas e se reconfigurem as estruturas legais (JENKINS; GREEN; FORD, 2014).

Essas mudanças são marcadas pelo surgimento de serviços gratuitos de streaming e compartilhamento de vídeos, que, a exemplo do YouTube, (que nasce em 2005 e chega ao Brasil em 2006), tensionaram as lógicas de produção e distribuição do mercado/campo audiovisual. É também no ano de 2006 que se inicia o processo de digitalização dos meios de produção nos cinemas e começa-se a discutir, inclusive no campo das políticas públicas, a migração das produções e exibições em película para meios digitais. O barateamento promovido pela digitalização, além da necessidade de formar mão de obra qualificada para atuar no emergente mercado audiovisual brasileiro dos anos 2000, também culminaria num esforço das instituições públicas (e privadas) para a criação de cursos de linguagem audiovisual Brasil adentro, voltados tanto para a linguagem de live action quanto para animação. 


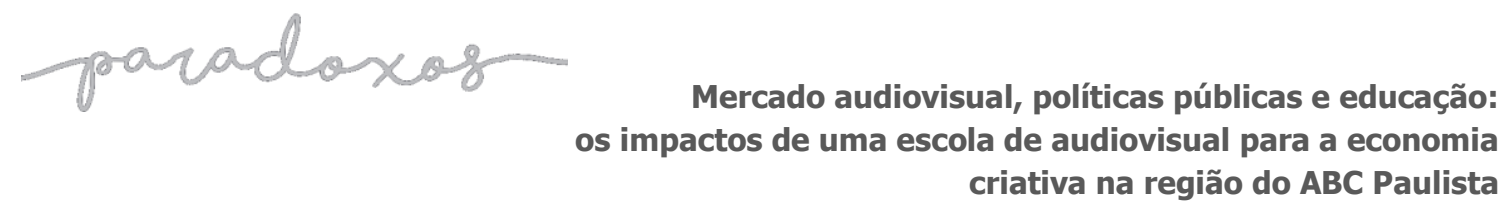

SZABO, SCABIN, 2021

O advento do cinema digital somado a políticas públicas para o ensino inaugurou um quadro diferenciado para as escolas de cinema e audiovisual brasileiras com a criação de 40 Instituições de Ensino Superior (IES), crescendo mais de $250 \%$ em menos de 8 anos. Para Universidades Públicas o barateamento dos insumos e equipamentos digitais, comparados com os requeridos anteriormente pelo uso da película, permitiu a qualificação das atividades dos cursos, particularmente para a experimentação e prática dos alunos e para as particulares como forma de atração de estudantes sem enormes custos operacionais (SILVA, 2012, p. 205).

Deve-se observar, ainda, que a necessidade de formação de mão de obra qualificada está intimamente ligada ao crescimento da demanda por produções nacionais que se consolida a partir da principal iniciativa da ANCINE, a criação da Lei 12.485, a "Lei do Cabo", com o fortalecimento do FSA e consequente modificação do cenário produtivo e exibidor brasileiro ${ }^{8}$.

Para além das políticas públicas, a evolução das tecnologias de captação de áudio e vídeo e a digitalização do conteúdo audiovisual promoveram um barateamento dos custos em toda a cadeia (da produção à distribuição), facilitando a entrada de novos atores no mercado e permitindo tanto o aumento da quantidade de obras produzidas quanto a criação de novas janelas de exibição diferentes das tradicionais, como canais de Videos on Demand (VoD) pagos e gratuitos, sendo que a distribuição por canais online tornou possível o mercado da "cauda longa" (ANDERSON, 2006), ao reduzir os custos de produção, divulgação e distribuição, fortalecendo o mercado de nicho.

Inicia-se também um processo de convivência entre atores midiáticos tradicionais e novos atores, muitas vezes até amadores, gerando por vezes uma via de mão dupla na qual conteúdos que se iniciam nas mídias digitais passam a convergir para as mídias tradicionais e ganham maior impulso quando isso ocorre. Por sua vez, os conteúdos das mídias

\footnotetext{
${ }^{8}$ Não obstante, convém observar que os incentivos dos últimos 25 anos, que levantaram o movimento da Retomada do Cinema Brasileiro, encontram-se ameaçados, uma vez que o Governo Bolsonaro não tem operacionalizado as linhas de investimento do Fundo Setorial do Audiovisual (FSA), e as produções nacionais com verba federal estão com prestações de contas paradas na ANCINE, comprometendo seus lançamentos e a comercialização das obras. Tal situação contrasta com o que vinha ocorrendo ao longo da última década, período em que se estabeleceu uma política pública clara para a pesquisa e inovação do setor audiovisual, cujos frutos já apareceram não somente na quantidade de produções, mas no reconhecimento nacional e internacional de crítica e público.
} 
tradicionais ganham impulso graças à relação que o público cria nas mídias digitais. Por fim, elimina-se a fronteira entre consumidor e receptor, e os papéis dos atores na cadeia ficam “misturados" (JENKINS; GREEN; FORD, 2014).

No caso brasileiro, a digitalização, somada a um investimento robusto de recursos públicos em toda a cadeia de produção, também permitiu a entrada de novos atores e democratizou e ampliou o mercado audiovisual especialmente a partir do início da segunda metade dos anos 2000. Não à toa, o mercado audiovisual brasileiro apresenta crescimento, apesar da crise econômica e financeira enfrentada no país ${ }^{9}$.

Em suma, todos esses fatores (entusiasmo da digitalização, real possibilidade do barateamento dos meios de produção audiovisual e expansão das plataformas de distribuição e consumo de conteúdos audiovisuais, além da injeção de recursos públicos para a produção e distribuição de conteúdos nacionais) acenderam a chama para que projetos variados com enfoque na ampliação e democratização do mercado audiovisual viessem à luz, incluindo centros diversos de produção, manutenção de espaços e a criação de escolas de cinema e audiovisual Brasil adentro.

\section{O CAV e o fomento da economia criativa no ABC paulista}

Na cidade de São Bernardo do Campo, se, por um lado, os prédios que restaram da antiga Cia Cinematográfica Vera $\mathrm{Cruz}^{10}$ são o símbolo da tentativa frustrada de criação da Hollywood Brasileira aos moldes modernos na década de 1950, por outro, a presença física das edificações na avenida Lucas Nogueira Garcez, a menos de dois

\footnotetext{
${ }^{9}$ Até 2019, o setor audiovisual mostrou-se como um dos segmentos econômicos que mais crescia no país, com taxa média de 8,8\%. Apesar disso, o atual governo federal não tem demonstrado interessado em regular o Video on Demand (VoD), campo para onde a produção de conteúdo migra a passos cada vez mais largos. Esse tipo de política, somada aos cortes e desarticulações na Ancine, coloca em risco mais de 20 anos de investimentos de sucesso (GEISLER, 2020).

${ }^{10}$ Referida como "A Hollywood Brasileira" ou "O mito do Cinema Industrial", a Vera Cruz marcou a tentativa de criação de um cinema industrial paulista na metade do século XX. A Vera Cruz representava também uma tentativa de trazer prestígio cultural relevante para uma sede fora da então capital Rio de Janeiro, colocando São Paulo não apenas como centro industrial, mas também como polo produtor de cultura e arte. Não por acaso, Franco Zampari, o fundador, era industrial já estabelecido, e a Companhia foi fundada em uma antiga fazenda de Francisco Matarazzo Sobrinho (CALIU, 2002). Embora ainda exista do ponto de vista legal, como empresa detentora do nome e do acervo de filmes, a jornada de produções de obras cinematográficas da Vera Cruz encerrou-se em 1954, quando o Banco do Estado de São Paulo (BANESPA) liquidou a companhia, que não teve tempo de colher os frutos de seus maiores sucessos, O Cangaceiro e Sinhá Moça, para poder quitar as dívidas e seguir em frente (MARTINELLI, 2002).
} 
quilômetros do centro da cidade, ainda mantém aceso o imaginário da presença de um estúdio de cinema de grande porte na região, evidenciando o desejo e a possibilidade de realizar filmes na região do $\mathrm{ABC}$ paulista.

Dentre inúmeras tentativas de revitalização da Companhia que não saíram do papel, os anos 2000 marcam o início de uma discussão promissora que propôs um calendário em fases para que a revitalização ocorresse; o projeto original da Nova Vera Cruz previa a revitalização dos estúdios, a construção de um teatro, a constituição de um espaço para uma incubadora de empresas voltadas para o setor criativo, bem como a implementação de um Centro de Audiovisual, que seria composto por uma escola e uma unidade responsável por produções audiovisuais.

Assim, em 2012, foi inaugurada a primeira etapa do projeto Nova Vera Cruz com o início das atividades do Centro de Audiovisual de São Bernardo do Campo - mais conhecido pela sigla "CAV" -, um projeto de cursos de formação gratuita em audiovisual que oferece cursos de 800 horas nas áreas de audiovisual live action e animação ${ }^{11}$. Embora o projeto original vinculasse o CAV à revitalização dos Estúdios Vera Cruz, as etapas da revitalização dos estúdios, da construção de um teatro e da constituição de um espaço para uma incubadora de empresas voltadas para o setor criativo acabaram sendo deixadas de 1 lado $^{12}$.

Para dimensionar os impactos do Centro de Audiovisual de São Bernardo do Campo para a economia criativa na região do $\mathrm{ABC}$ paulista, consideramos neste trabalho dois indicadores principais: (1) abertura de novas empresas, atuantes no setor

\footnotetext{
${ }^{11}$ Além da escola, o CAV dispõe de um "Núcleo de Produção" que realiza produções independentes, produções para a Secretaria de Cultura da cidade e apoia produtores locais.

${ }^{12}$ O Projeto Nova Vera Cruz visava a revitalizar o espaço onde se encontram os Pavilhões Vera Cruz, para que voltassem a funcionar como estúdios audiovisuais plenamente equipados. Para tal, previu-se que a revitalização ocorreria em três fases, sendo que a primeira delas seria a inauguração do $\mathrm{CAV}$, que foi erguido via convênio entre a Prefeitura de São Bernardo do Campo (PMSBC) e o então Ministério da Cultura (BRASIL, 2010). O recurso federal foi utilizado para montar e equipar o CAV e para o pagamento dos recursos humanos para manutenção do Centro por um período de dois anos. Após este período, seria realizada a concessão pública da Vera Cruz e do CAV. Idealmente, a concessionária exploraria comercialmente os estúdios e o espaço da Vera Cruz como um todo e como contrapartida ao município, seria responsável pelo funcionamento do $\mathrm{CAV}$ e da incubadora de empresas. Caberia à Prefeitura entregar à concessionária o Teatro montado e o espaço da Vera Cruz com as licenças liberadas para que a concessionária pudesse realizar as obras necessárias nos pavilhões para abrigar os estúdios. A licitação da concessão ocorreu, sendo vencedora do certame a empresa TELEM S.A (GUIA DA CIDADE, 2015), contudo, após atuar por pouco mais de um ano e meio, a concessionária não cumpriu as contrapartidas e sequer iniciou qualquer obra na Vera Cruz (BALDINI, 2015). O Teatro também nunca saiu do papel. Em 2017, após mudança de gestão em São Bernardo do Campo, o contrato entre a concessionária e a Prefeitura foi desfeito, enterrando de vez o projeto original. Entretanto, a PMSBC, após cortar parte significativa de sua equipe e extinguir o período vespertino de aulas, manteve ativo o CAV, que ainda resiste.
} 
audiovisual, em cuja constituição seja possível identificar a influência do CAV; e (2) presença de egressos do CAV entre proponentes contemplados em editais municipais de cultura, especialmente em São Bernardo do Campo.

Em relação ao primeiro indicador, localizamos, até junho de 2021, mais de 20 CNPJs abertos apenas em São Bernardo do Campo voltados a alguma atividade audiovisual cujo nascimento pode ser relacionado à influência do CAV. Mais especificamente, com base nos resultados de uma pesquisa realizada internamente pelo Centro de Audiovisual de São Bernardo do Campo em 2021, com o objetivo de acompanhamento de seus egressos e conforme informações fornecidas, para as finalidades desta pesquisa, pela Secretaria de Cultura e Juventude de São Bernardo do Campo, foi possível identificar 23 egressos que atuam profissionalmente prestando serviços formalmente vinculados à atividade audiovisual, ou seja, têm empresa aberta em seu nome e emitem nota fiscal (CENTRO DE AUDIOVISUAL DE SÃO BERNARDO DO CAMPO, 2021) ${ }^{13}$.

Observou-se ainda a criação de um estúdio ${ }^{14}$, de algumas produtoras e de uma série de coletivos ativos, porém informais (do ponto de vista jurídico), que se articulam na região. A título de exemplos, citam-se os coletivos Kromaki Produções e Ficcional Filmes. O primeiro é formado e idealizado por Amanda Justo e Pâmela Domici, egressas em 2020 pelo CAV. Ainda que recente, o grupo já realizou o curta-metragem $O$ medo de ser quase e atualmente levanta fundos via rifa para a produção do curtametragem independente Entre nós dois. Já a Ficcional Filmes vem produzindo obras independentes desde 2016. Encabeçada pelos egressos Rafael Van Hayden (Rafael Gonzalez da Silva) e Valdir Bernardo Jr (além de contar com a participação constante e frequente de vários outros egressos e egressas), o coletivo já realizou filmes como

\footnotetext{
${ }^{13}$ Para além dos egressos, pode-se destacar também educadores do CAV responsáveis pela abertura de CNPJs, como Camilla Martinez de Oliveira e Daniel Maciel, ainda atuantes no Centro. Camilla é moradora de São Bernardo do Campo e abriu sua MEI em 2013, para poder atuar junto ao CAV como educadora. Contudo, com o passar dos anos, passou também a dirigir filmes e realizar trabalhos de produção audiovisual. Já Daniel Maciel é roteirista proprietário da ARQUITRAMA. Fundada em 2012, antes da inauguração do CAV, a empresa tinha sede em São Paulo capital. Após algum tempo atuando no CAV, Daniel mudou-se para São Bernardo e transferiu sua empresa para a cidade (BRASIL, s.d.).

${ }^{14}$ O estúdio Neblina Estúdios foi fundado pelo egresso do CAV Riba Dantas (José Ribamar Libródio Dantas), que ingressou no CAV no período vespertino em agosto de 2014 e se formou em dezembro de 2015. Em 2018, abriu uma MEI, cujo nome fantasia era Riba Dantas Fotografias. Atualmente esta empresa é uma ME. Já no ano de 2021, abriu a Neblina Estúdios Ltda., ampliando sua atuação profissional (BRASIL, s.d.).
} 
Fantasma Magnético e Tripofobia, obras de terror, que vêm sendo exibidas e premiadas em diversos festivais de cinema brasileiros e estrangeiros.

Além disso, o CAV também se mostra como um ponto de encontro entre artistas locais e, por isso, uma incubadora de uma série de outros projetos. É o caso, por exemplo, do projeto da animação Blu, vencedor do prêmio de Produção de Curta Metragem da Lei Aldir Blanc de São Bernardo do Campo. Gestado dentro de sala de aula, foi o projeto de conclusão de curso da proponente Greiciane Alves de Souza em parceria com colegas. Outro exemplo a ser citado é o longa-metragem documental Sem chão sem medo. O longa, que segue circulando em festivais de cinema, foi idealizado por alunos do CAV que atualmente formam o coletivo Murmur filmes. Produzido com recursos próprios de seus idealizadores, o projeto nasceu a partir do interesse dos alunos pela ocupação "Povo Sem Medo", do MTST, ocorrida em 2018 em terreno vizinho ao CAV. Embora não tenha sido um projeto formal do CAV, seu nascimento ocorreu dentro do espaço do Centro e a partir das relações por ele propiciadas. Atualmente, o coletivo Murmur filmes está em fase de formalização e possui dois curtas-metragem em fase de produção.

Já em relação ao segundo indicador considerado neste trabalho, observamos, com base no exame dos editais municipais da Lei Aldir Blanc ${ }^{15}$ lançados em 2020, que ao menos $58 \%$ dos projetos contemplados na linha de produção de curtas-metragens ${ }^{16}$ foram propostos por egressos do $\mathrm{CAV}^{17}$. Dentre tais propostas, identificamos a presença de produções vinculadas a diferentes gêneros audiovisuais, incluindo ficções, documentários e animações. Para além desses casos, não obstante, convém notar que quase todos os projetos contemplados nessa linha têm em sua equipe pessoas que passaram direta ou indiretamente pela instituição.

\footnotetext{
15 A Lei no 14.017, de 29 de junho de 2020, denominada Lei Aldir Blanc, foi criada com o intuito de promover ações para garantir uma renda emergencial para trabalhadores da Cultura e manutenção dos espaços culturais brasileiros durante o período da pandemia da Covid-19. A lei disponibilizou recursos do Fundo Nacional da Cultura para os estados e todos os municípios que tivessem interesse em receber e executar o recurso. O inciso III da lei previa a possibilidade dos municípios e estados lançarem editais de fomento.

16 Tais números baseiam-se no cruzamento entre os dados públicos referentes aos resultados dos editais e os registros internos de egressos do CAV, conforme informações fornecidas, para as finalidades desta pesquisa, pela Secretaria de Cultura e Juventude de São Bernardo do Campo.

17 Convém observar que não puderam se inscrever nos editais da lei Aldir Blanc de São Bernardo do Campo titulares de cargos efetivos, comissionados, empregados temporários e terceirizados da Secretaria de Cultura e Juventude, seus cônjuges, parentes consanguíneos ou afins até $3^{\circ}$ grau; dessa forma, alguns educadores e técnicos atuantes no CAV não puderam concorrer como proponentes (SÃO BERNARDO DO CAMPO, 2020).
} 
Em outros editais, como "Linguagens Livres" ou "Cultura em Casa"18, cujos objetos eram mais abertos e poderiam ser propostos projetos que abarcassem linguagens audiovisuais, também identificamos a presença de "cavianos" entre os proponentes contemplados, bem como membros de equipe. Ainda há a presença de pessoas ligadas ao CAV entre os contemplados em editais de outras linguagens, como literatura, fotografia, culturas urbanas, circo, cultura em casa, entre outros ${ }^{20}$.

Para além das fronteiras do município de São Bernardo do Campo, nas cidades vizinhas que compõem o $\mathrm{ABC}$, também se observam projetos contemplados com a participação de alunos e egressos do $\mathrm{CAV}$, bem como forte presença nas equipes de produção. Em cidades menores, como Ribeirão Pires e, especialmente em Rio Grande da Serra, um grupo de egressos foi essencial na articulação política para que suas cidades executassem os recursos da Lei Aldir Blanc ${ }^{21}$.

Finalmente, como indicadores complementares, podemos citar a atuação de egressos que têm se dedicado à produção de conteúdo audiovisual para plataformas digitais, especialmente com a criação de canais no YouTube, voltados tanto ao ensino de audiovisual e cultura quanto de conteúdos outros. Destacam-se, ainda, diversos casos de filmes produzidos por alunos do CAV (como parte das atividades realizadas no projeto) e egressos que têm sido premiados em festivais nacionais e estrangeiros de cinema.

A título de exemplificação, dentre os curtas premiados em festivais, destacam-se as obras Clausura, documentário dirigido por Mariana França e Gildo Antônio, e A Linha, animação dirigida por Francisco Lira. Já no campo do VoD, podemos citar os canais do YouTube Cacheia Vai, fundado por Eliete Santos, que aborda a estética afro-brasileira, e Amor Livre, criado por Sayuri Irie, cuja temática principal são relacionamentos amorosos e

\footnotetext{
${ }^{18}$ São Bernardo do Campo lançou 19 editais, nas mais diversas áreas, havendo um edital que contemplou 25 projetos de produção de curtas-metragens com premiação de $\mathrm{R} \$ 20.000,00$.

${ }^{19}$ Nomenclatura informal adotada por alunos e professores para se referir às pessoas que passaram pelo Centro de Audiovisual de São Bernardo do Campo (CAV).

${ }^{20}$ Com base no exame cruzado das publicações do Diário Oficial do Município de São Bernardo do Campo (SÃO BERNARDO DO CAMPO, 2021) e dos registros internos do CAV, conforme informações fornecidas, para as finalidades desta pesquisa, pela Secretaria de Cultura e Juventude de São Bernardo do Campo, foi possível identificar os alunos regularmente matriculados ou egressos com participação nos projetos contemplados.

${ }^{21}$ Referimo-nos à atuação da egressa Josi Reis, moradora de Rio Grande da Serra, que teve papel importante na articulação política de sua cidade para que se executassem os recursos da Lei. Ela é diretora do documentário Cria da Mata, lançado em abril de 2021, fruto dos recursos da Lei. Além dela, outros egressos do CAV fazem parte da equipe de produção do filme.
} 


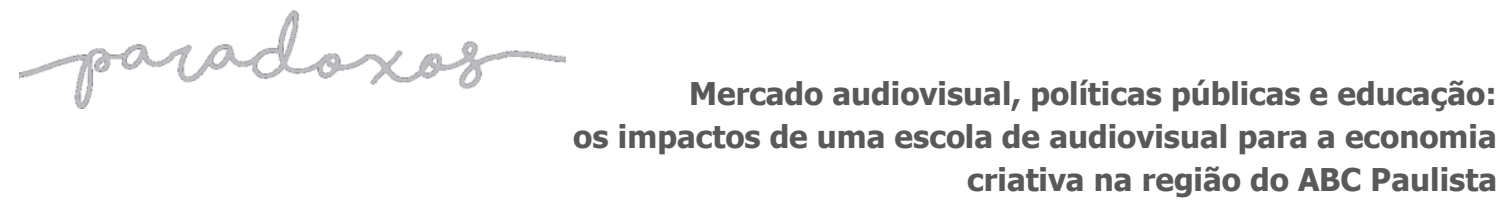

SZABO, SCABIN, 2021

interpessoais. No caso de Amor Livre, a visibilidade de Sayuri em seu canal fez com que ela fosse convidada a participar do elenco do reality show televisivo Se Sobreviver, Case (Multishow); a participação no programa, por sua vez, aparentemente pode, por sua vez, ter gerado mais engajamento e audiência para o canal.

\section{Considerações finais}

$\mathrm{O}$ artigo buscou apresentar resultados parciais de uma pesquisa de mestrado atualmente em curso no Programa de Pós-graduação em Comunicação da Universidade Anhembi Morumbi, em São Paulo, com foco na recuperação, com base em pesquisa bibliográfica, das políticas públicas de incentivo ao mercado audiovisual brasileiro recente e do contexto de transformações socioculturais decorrentes da digitalização e expansão do mercado audiovisual no Brasil.

Considerando o aumento da oferta de iniciativas voltadas ao ensino e formação de profissionais para atuação no campo audiovisual, o trabalho focalizou o caso o Centro de Audiovisual de São Bernardo do Campo (CAV), escola uma escola pública de audiovisual em atividade, desde 2012, na região do ABC paulista. A partir do exame de dois indicadores principais (estímulo à abertura de novos negócios e participação de egressos do projeto em editais municipais de cultura), buscamos compreender quais os impactos do CAV para a economia criativa de São Bernardo do Campo e cidades vizinhas.

Dessa forma, o trabalho identificou a criação de CNPJs voltados a atividades audiovisuais em São Bernardo do Campo cujos envolvidos apresentam alguma ligação com o CAV. Além disso, constatou uma presença expressiva de egressos e pessoas vinculadas ao $\mathrm{CAV}$ entre os proponentes e equipes de projetos contemplados em editais municipais de cultura na região do ABC no ano de 2020.

Tais impactos sugerem, para além do incremento da economia criativa em uma região de São Paulo, que o CAV, até mesmo por sua natureza de curso público e gratuito localizado na região metropolitana de São Paulo (fora da capital do estado), favorece a diminuição das desigualdades existentes no acesso aos processos de produção e circulação de mídia audiovisual entre diferentes camadas sociais e contextos regionais. Nesse sentido, os impactos da atuação do Centro no campo audiovisual podem ser relacionados ainda à 


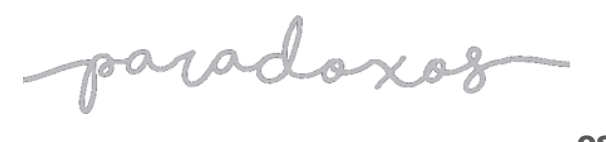

Mercado audiovisual, políticas públicas e educação: os impactos de uma escola de audiovisual para a economia criativa na região do $\mathrm{ABC}$ Paulista

SZABO, SCABIN, 2021

formação de público, tanto no sentido clássico do cinema (público que vai ao cinema e paga ingresso) quanto na formação de um público participativo, isto é, um público que toma parte na cultura audiovisual, produzindo e compartilhando conteúdo.

Num mundo em que a produção e a circulação de conteúdos estão cada vez mais imbricadas e que o ecossistema midiático está cada vez mais complexo, a presença de um espaço que desenvolve as competências para a atuação em uma cultura de convergência, de participação e de propagabilidade de mídia - para usarmos os termos de Jenkins, Green e Ford (2014) - é essencial para que se viabilize a entrada de novos atores no mercado. Isso só se torna possível, porém, como procuramos evidenciar ao longo do artigo, mediante políticas públicas consistentes de fomento à cultura, cujo potencial de geração de renda, criação de empregos e produção de receitas, para além do favorecimento ao desenvolvimento e a diversidade cultural, passa a ocupar o centro dos holofotes à luz dos debates sobre economia criativa.

\section{Referências}

ANCINE. Uma nova política para o audiovisual: Agência Nacional do Cinema, os primeiros 15 anos. Agência Nacional do Cinema, Rio de Janeiro, 2017. Disponível em: https://www.gov.br/ANCINE/pt-br/centrais-de-conteudo/publicacoes/livros/ANCINE-15anos-web-final-em-baixa2.pdf/view. Acesso em: 04 set. 2021.

ANDERSON, Chris. A Cauda Longa. 5.ed. Rio de Janeiro: Elsevier, 2006.

BALDINI, Leandro. Marinho ameaça Telem para manter Vera Cruz. Diário do Grande $A B C$, Política, 9 out. 2015, [S.p.]. Disponível em:

https://www.dgabc.com.br/Noticia/1593244/marinho-ameaca-telem-para-manter-veracruz. Acesso em: 11 set de 2021

BRASIL. Consultas Pessoa Jurídica. Receita Federal. [S.d.]. Disponível em: https://www.gov.br/empresas-e-negocios/pt-br/redesim/consultas-pessoa-juridica. Acesso em: 11 set. 2021.

CASTELLS, Manuel. A sociedade em rede. Rio de Janeiro: Paz e Terra, 2000

BRASIL. EXTRATO DE CONVÊNIO No 730810/2009. SECRETARIA DO AUDIOVISUAL. Diário Oficial da União: seção 3, Brasília, DF, ano 147, n. 22, p. 10, 02 fev. 2010. Disponível em: http://anexos.datalegis.inf.br/tm/DO3_2010_02_02_integra.pdf. Acesso em: 12 set. 2021. 


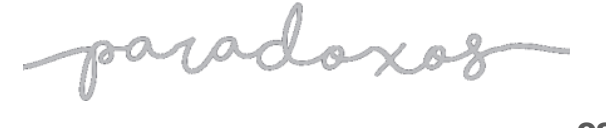
os impactos de uma escola de audiovisual para a economia criativa na região do $\mathrm{ABC}$ Paulista

SZABO, SCABIN, 2021

CENTRO DE AUDIOVISUAL DE SÃO BERNARDO DO CAMPO. Pesquisa de acompanhamento de egressos. Secretaria Municipal de Cultura de São Bernardo do Campo. 2021. [documento interno].

GEISLER, Daniela. Estado, Mercado e Cinema: A regulamentação do Condecine sobre o video on demand (VoD). São Paulo: Independente, 2020.

FUCK, M. P.; VILHA, A. M. Inovação Tecnológica: da definição à ação.

Contemporâneos: Revista de Artes e Humanidades, Santo André, v. 9, p. 1-21, jan.2012.

GATTI, André. RioFilme: uma distribuidora de filmes nacionais (1992-2000). Mnemocine, [S.l.], 18 Jul. 2008. Disponível em: http://www.mnemocine.com.br/index.php/cinemacategoria/24-histcinema/109-andre-gatti. Acesso em: 04 set. 2021.

GATTI, André. Distribuição e exibição na indústria cinematográfica brasileira (1993-2003). Tese (Doutorado em Multimeios). Universidade de Campinas, Campinas. 2005. Disponível em http://repositorio.unicamp.br/bitstream/REPOSIP/284789/1/Gatti_AndrePiero_D.pdf. Acesso em: 12 set. 2021

GUIA DA CIDADE. Companhia Vera Cruz volta a produzir cinema. Guia da Cidade, São Bernardo do Campo, ano 5, n. 53, p. 4-7, abr. 2015. Disponível em: https://www.saobernardo.sp.gov.br/documents/10181/389885/Edi\%C3\%A7\%C3\%A3o+53 +-+Abril.pdf/. Acesso em: 12 set. 2021.

HOWKINS, John. Economia criativa: como ganhar dinheiro com ideias criativas. São Paulo: M.Books, 2012.

JENKINS, Henry. Cultura da convergência. Trad. Susana Alexandria. São Paulo: Aleph, 2009.

JENKINS, Henry; GREEN, Joshua; FORD, Sam. Cultura da conexão: criando valor e significado por meio da mídia propagável. Trad. Patrícia Arnaud. São Paulo: Aleph, 2014.

LAHIRE, Bernard. "Campo". In: CATANI, Afrânio Mendes et al. (org.). Vocabulário Bourdieu. 1ed. Belo Horizonte: Autêntica, 2017. p. 64-66.

LÉVY, Piere. Cibercultura. São Paulo: Editora 34, 1999.

MARTINELLI, Sérgio. Vera Cruz, Imagens e Histórias do Cinema Brasileiro. São Paulo: Abooks, 2002.

MPA-AL; SICAV. O impacto económico do setor audiovisual brasileiro. Motion Picture Association América Latina, Sindicato Interestadual da Indústria Audiovisual, São Paulo, 2016. Disponível em: https://icabrasil.org/2016/files/557corporateTwo/downloads/LOW_ESTUDO_MPAAL_21x30_06-06-16.pdf. Acesso em: 04 set. 2021. 


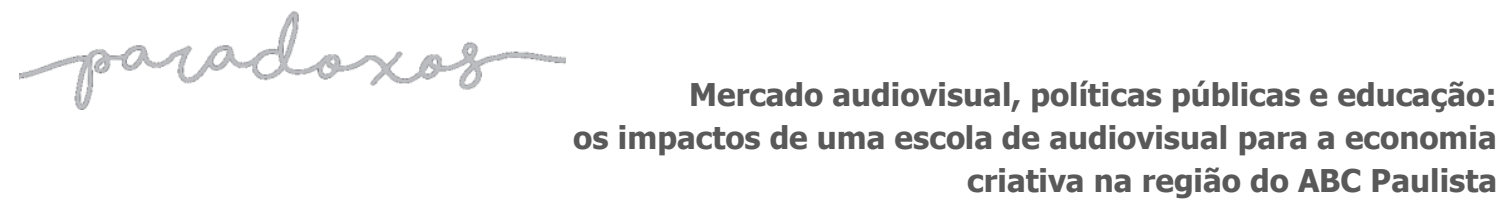

SZABO, SCABIN, 2021

PETHS, Lucas Lisboa. Horário Gratuito de Propaganda Eleitoral e Propaganda Partidária Gratuita: do surgimento à personalização na televisão brasileira. Anuário

Unesco/Metodista de Comunicação Digital, São Paulo, ano 17, n. 17, p. 63-76, jan./dez.

2013. Disponível em: https://www.metodista.br/revistas/revistas-

metodista/index.php/AUM/article/view/5501. Acesso em: 13 set. 2021.

PRIOLLI, Gabriel; CLARK, Walter. O Campeão de Audiência. São Paulo: Nova Cultural, 1991.

SÃO BERNARDO DO CAMPO. Editais. Lei Aldir Blanc. Secretaria de Cultura e Juventude. 2020. Disponível em: https://www.saobernardo.sp.gov.br/web/cultura/editais1. Acesso em: 11 set. 2021.

SÃO BERNARDO DO CAMPO. RESULTADO FINAL DOS EDITAIS DE PREMIAÇÕES REFERENTES À LEI FEDERAL No 14.017/2020. Notícias do Município: Edição 2199, São Bernardo do Campo, p. 24, 22 jan. 2021. Disponível em: https://www.saobernardo.sp.gov.br/documents/915728/1004719/NM+2199+de+22.01.2021++Paginas-24-25.pdf/18eb3118-ca5c-c71b-3c83-bc861ce94eac. Acesso em: 14 set. 2021.

SEBRAE. Como o Sebrae atua no segmento de Economia Criativa. Serviço de Apoio às Micro e Pequenas Empresas, Brasília, [S.d.]. Disponível em: https://www.sebrae.com.br/sites/PortalSebrae/segmentos/economia_criativa/como-osebrae-atua-no-segmento-de-economiacriativa,47e0523726a3c510VgnVCM1000004c00210aRCRD. Acesso em: 04 set. 2021.

SEBRAE. Estudo de Inteligência do Mercado Audiovisual Brasileiro. Serviço de Apoio às Micro e Pequenas Empresas, Brasília, 2015. Disponível em: https://bibliotecas.sebrae.com.br/chronus/ARQUIVOS_CHRONUS/bds/bds.nsf/30ec0866a 085430efaef28fb30ec4f93/\$File/5825.pdf. Acesso em: 04 set. 2021.

SILVA, Luciana Rodrigues. O Cinema Digital e seus Impactos na formação em cinema e audiovisual. Tese (Doutorado em Meios e Processos Audiovisuais). Universidade de São Paulo, São Paulo, 2012. Disponível em: https://www.teses.usp.br/teses/disponiveis/27/27161/tde10052013-162929/publico/LucianaRodrigues.pdf. Acesso em: 04 set. 2021.

TRINDADE, Teresa Noll. Documentário e Mercado no Brasil - da produção à sala de cinema. São Paulo: Alameda, 2010. 